\title{
Estudo epidemiológico da Dermatobia hominis (Diptera: Cuterebridae) em bovinos de produção leiteira no Município de Santa Maria, Rio Grande do Sul, Brasil
}

\author{
FABRICIO DESCONSI MOZZAQUATRO* e ARGEMIRO SANAVRIA**
}

\author{
EPIDEMIOLOGICAL STUDY OF Dermatobia hominis (DIPTERA: CUTEREBRIDAE) ON \\ DAIRY CATTLE IN A COMMUNITY OF SANTA MARIA, \\ RIO GRANDE DO SUL STATE, BRAZIL
}

With the purpose of studyng the seasonal variation and the population increase of Dermatobia hominis group's in bovines, the verification of nodes distribution caused by the grubs in the host's body area as well as the relationship between the quantity of D. hominis groups and the weather information, 79 rural properties in Santa Maria city were visited. In each property 10 animals were selected that were individually inspected. Results indicated that the highest parasitism numbers occurred during the warm months (from October to February). On the other hand, during the cold months (from April to September) the infective rates were lower or even none. Concerning the body areas, the front part showed 83,3\% of the nodes, while the back one presented just 16,4\% of them.

Key words: Epidemiology, Dermatobia hominis, cattle, myiasis, Brazil.

\section{INTRODUÇÃO}

As perdas econômicas causadas por doenças nos animais são elementos que limitam o desenvolvimento pecuário. Dentre os agentes etiológicos que atacam os bovinos nas Américas, nove são artrópodes, dentre os quais está a Dermatobia hominis que é considerada o terceiro ectoparasita de maior importância econômica no Brasil. ${ }^{1}$

Este trabalho objetivou estudar a variação sazonal e a dinâmica populacional de larvas de D. hominis em bovinos leiteiros de diferentes regiões fisiográficas do município, verificar a distribuição das nodulações provocadas pelas larvas de acordo com a área corporal do hospedeiro, bem como correlacionar a incidência do berne com dados meteorológicos da região de Santa Maria, RS.

\section{MATERIAL E MÉTODOS}

Foram visitadas 79 propriedades rurais localizadas no município de Santa Maria sendo estas pertencentes a COOPROL (Cooperativa Produtora de Leite). Estas propriedades estão distribuídas de acordo com linhas de entrega de leite à Usina Escola de Laticínios da UFSM.

Em cada propriedade foram selecionados aleatoriamente dez bovinos em produção e o intervalo de visita a cada propriedade foi em média de 30 dias.

Os animais selecionados foram inspecionados individualmente, sendo então feita a contagem

\footnotetext{
Curso de Pós-Graduação em Medicina Veterinária, Universidade Federal de Santa Maria, Santa Maria, RS, Brasil.

** Departamento de Epidemiologia e Saúde Pública, Instituto de Veterinária, Universidade Federal Rural do Rio de Janeiro, Caixa Postal 74556, CEP 23851-970, Seropédica, RJ, Brasil. E-mail: sanavria@ufrrj.br
} 
dos nódulos e posterior mapeamento destes de acordo com a localização na superfície corporal do animal. Os dados meteorológicos foram obtidos através do Departamento de Fitotecnia da UFSM onde se encontra-se localizada a estação meteorológica.

Durante todo o decorrer do presente estudo não houve qualquer interferência sobre o manejo e a utilização de métodos de aplicação de ectoparasiticidas em nenhuma das propriedades visitadas.

\section{RESULTADOS E DISCUSSÃO}

Analisando as propriedades visitadas, verificou-se que há uma predominância do perfil familiar, caracterizada por pequenos rebanhos, com produção de leite relativamente baixa e poucas propriedades com assistência técnica de um médico veterinário.

Analisando as Figuras 1 e 2, observa-se que os meses de maior parasitismo correspondem outubro a fevereiro, período este onde as temperaturas são mais elevadas. $\mathrm{O}$ período

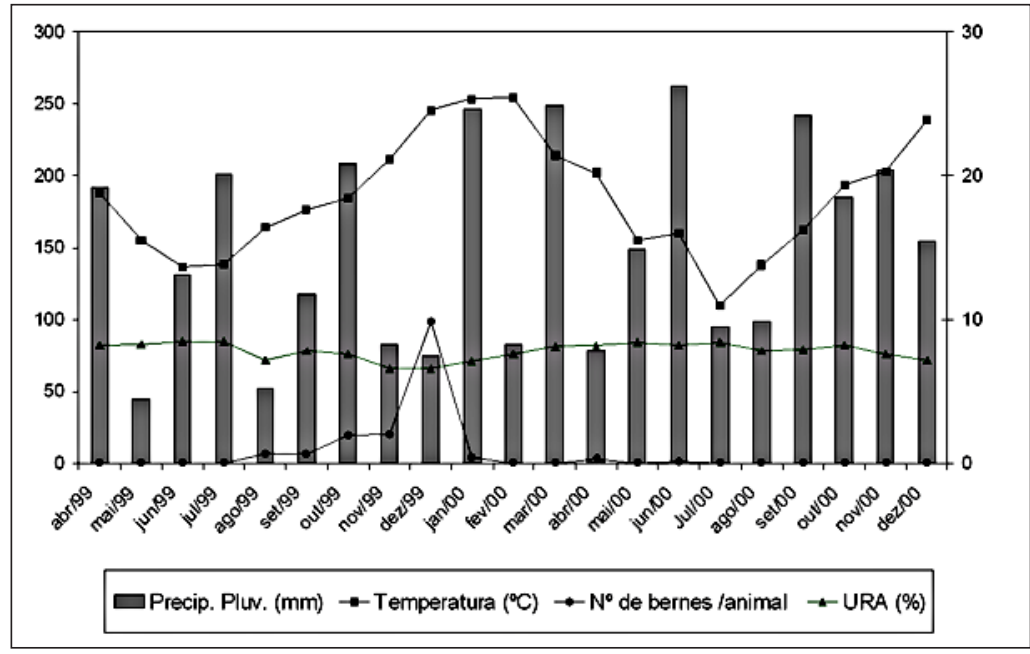

Figura 1. Influência da precipitação pluviométrica, temperatura e umidade relativa do ar sobre o número médio de nódulos de bernes/animal, no período de abril de 1999 a dezembro de 2000, no município de Santa Maria, RS.

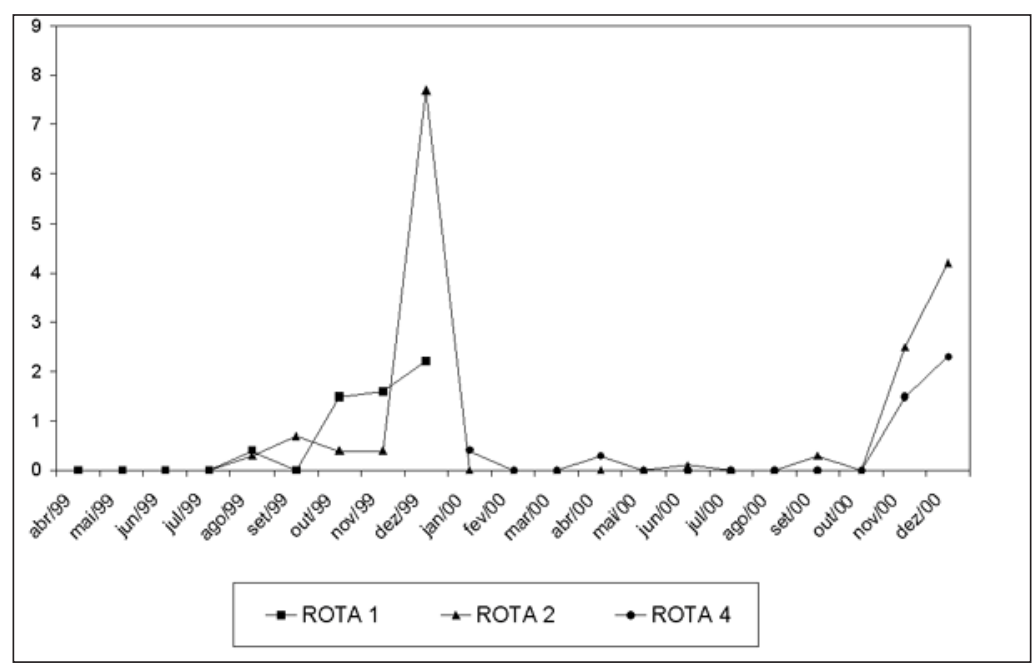

Figura 2. Contagem do número de nódulos de berne/animal, no período de abril de 1999 a dezembro de 2000, nas diferentes rotas estudadas. Santa Maria, RS. correspondente aos meses de abril a setembro, onde ocorreu baixas taxas infectivas, correspondem as estações de outono e inverno, onde ocorre uma diminuição considerável na temperatura, com altas precipitações pluviométricas. Estes resultados estão de acordo com a literatura, onde observou-se maiores picos de infestação de berne em períodos onde ocorre elevados índices de temperatura, umidade e precipitação pluviométrica. $^{2-5}$

Com relação à porção do corpo onde foram contados os maiores números de berne, o trem anterior apresentou 83,3\% dos nódulos enquanto que no posterior apenas $16,4 \%$ (Tabela 1). Estes resultados se mostram um pouco inferiores aos obtidos por outro autor, ${ }^{6}$ que observou $95 \%$ das larvas de $D$. hominis na porção anterior dos bovinos, mostrando a predileção do parasita pelo trem anterior dos animais.

As regiões onde foram encontradas maiores concentrações de berne foram as regiões das patas com $34,5 \%$, região do tórax e paleta com $27,8 \%$ e costela com $13,5 \%$ das nodulações. 
Tabela 1. Percentual de nódulos de Dermatobia hominis contados por região do corpo do animal

\begin{tabular}{llcc}
\hline Área & \multicolumn{1}{c}{ Região do animal } & Número de nódulos & Porção \\
\hline A & Orelha Cabeça Pescoço Barbela & $7,5 \%$ & Anterior $(83,3 \%)$ \\
G & Pata dianteira & $34,5 \%$ & \\
B & Tórax Paleta & $27,8 \%$ & \\
C & Costela Flanco & $13,5 \%$ & \\
D & Anca Períneo Cauda & $9,0 \%$ & Posterior $(16,4 \%)$ \\
E & Pata traseira & $2,2 \%$ & \\
F & ÚbereVentre & $5,2 \%$ & \\
\hline
\end{tabular}

RESUMO

Com o objetivo de estudar a variação sazonal de Dermatobia hominis em bovinos, verificou-se a presença e distribuição dos nódulos em diferentes áreas do corpo dos animais nos meses do ano. Foram visitadas 79 propriedades rurais no município de Santa Maria, Rio Grande do Sul. Em cada propriedade foram selecionados dez animais, sendo inspecionados individualmente. Os resultados indicaram alto parasitismo durante os meses de verão (outubro a fevereiro) e menores taxas de infecção nos meses de inverno (abril a setembro). Com relação à área corporal, $83,3 \%$ da frequiência de nódulos do berne concentrou-se na região anterior e 16,4\% na região posterior do animal.

\section{REFERÊNCIAS}

1.- OMS/OPS. Diagnóstico de la salud animal en las Americas. 1. Washington, D.C., 1983, 223 p.

2.- LOMBARDERO O J, FONTANA B A J. La ura (Dermatobia hominis) en la provincia de Formosa. Gac Vet 1968; 30: 297-306.

3.- MAGALHÃES F E P, LESSKIU C. Efeito do controle do berne sobre o ganho de peso e qualidade dos couros em novilhos de corte. Pesq Agropec Bras 1982; 17: 329-36.

4.- MAIA A A M, GUIMARÃES M P. Distribuição sazonal de larvas de Dermatobia hominis (Linnaeus Jr., 1781) (Diptera: Cuterebridae) em bovinos de corte da Região de Governador Valadares - Minas Gerais. Arq Bras Med Vet Zoot 1985; 37: 469-75.

5.- MAGALHÃES F E P, LIMA J D. Freqüência de larvas de Dermatobia hominis (Linnaeus Jr., 1781) em bovinos de Pedro Leopoldo, Minas Gerais. Arq Bras Med Vet Zoot 1988; 40: 361-67.

6.- OLIVEIRA C M B. Variações mensais das infestações de bovinos por larvas de Dermatobia hominis em Viamão, RS. Arq Fac Vet UFRGS 1985; 13: 61-4.

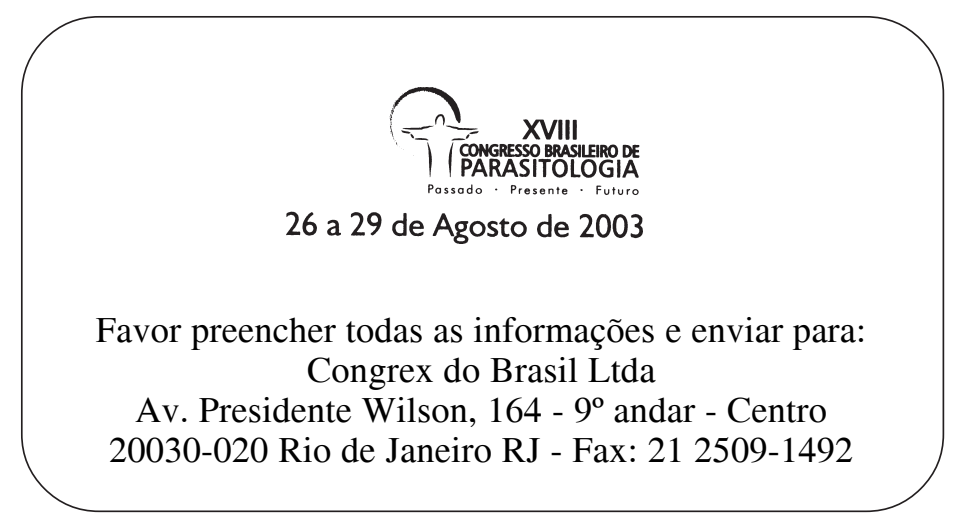

